\title{
ОСНОВНЫЕ ПРОБЛЕМЫ РАЗВИТИЯ ГРУЗОПОТОКОВ СЕВЕРНОГО МОРСКОГО ПУТИ
}

\section{(C) 2019 Пухова Марина Михайловна}

кандидат экономических наук, доцент, заместитель директора Института аспирантуры Финансовый университет при Правительстве Российской Федерации, Россия, Москва

E-mail:mpuhova@fa.ru

\section{(c) 2019 Харчилава Хвича Патаевич}

кандидат экономических наук, доцент Департамента корпоративных финансов и корпоративного управления, первый заместитель декана Факультета экономики и финансов топливно-энергетического комплекса

Финансовый университет при Правительстве Российской Федерации, Россия, Москва

E-mail: HPHarchilava@fa.ru

\section{(c) 2019 Башков Дмитрий Юрьевич}

студент 2 курса, группа МБЭК2-1

Финансовый университет при Правительстве Российской Федерации, Россия, Москва E-mail: d.bashkov.u@gmail.com

В статье отражены основные современные проблемы развития Северного морского пути и основные характеристики его грузоперевозок. Проанализированы такие проблемы как влияние климатических условий на формирование транспортной системы Северного морского пути, необходимость увеличения его грузоперевозок, развитие необходимой инфраструктуры для создания комплексной логистической системы, в т.ч. с использованием ледоколов. Отмечена необходимость развития Северного морского пути с точки зрения социальных инфраструктурных аспектов. В этих условиях для многих арктических районов морской транспорт является единственным средством обеспечения массовых перевозок грузов, а Северный морской путь - главным фактором развития международных и межрегиональных экономических, культурных и социальных связей.

Ключевые слова: Морские грузовые перевозки, ледоколы, климат, Северный морской путь (СМП), трансарктическое сообщение, межконтинентальное сообщение, российские ледоколы, морская инфраструктура СМП.

В настоящее время проблема развития Северного морского пути (далее- СМП) является одной из наиболее актуальной и дискуссионной, а формирование эффективно функционирующей Арктической транспортной системы выделяется в качестве приоритетной задачи социальноэкономического развития страны. Стоит отметить, что в конце XX ст. в экономике России произошли радикальные изменения, связанные с переходом от целевого критерия управления к критерию экономической эффективности. Данный сдвиг отразился на развитии Арктического морского транспорта, например, пик активности использования данного транспорта пришелся на 1987 год (было перевезено около 6,5 млн. тонн), в 1999 году он сократился до 1,6 млн. тонн (в 4 раза меньше). Однако в последние годы наблюдается тенденция к постепенному росту грузопотоков, в том числе транзитных, но это не отвечает геоэкономическим вызовам и возможностям российской Арктики. Так, в Баренцевом море в связи с разработкой месторождения Варандей в 2010 году было перевезено 7,5 млн. тонн нефти. Резкое снижение (до 3,9 млн. т) произошло в 2011 году из-за сокращения добычи на Угзно-Хильчуюсском месторождении. Однако этот сектор не вошел в воды СМП, являясь при этом базовым элементом всего движения. Следует отметить, что до 2010 года грузопоток через СМП не превышал 2 млн. тонн, из них более 80\% приходилось на Карское море за счет деятельности ОАО «Норильский никель» и экспорта нефти, а также газового конденсата из Обского залива. Объем перевозок по СМП в 2011 году, по данным администрации СМП, составил 3,1 млн. тонн, в том числе экспорт 806 тыс. тонн - 26\% от общего 
объема перевозок; доставка 1471 тонны - 47,2\% с учетом международных перевозок по СМП; транзит 834 тонн - 26,8\% перевозок в районах, прилегающих к СМП, грузопоток в 2011 году осуществлялся в основном по ледовым участкам (в соответствии со статьей 234 Конвенции $\mathrm{OOH}$ по морскому праву в отношении вод особых нормативных условий) в Печорском море (юго-восток Баренцева моря) - 3,9 млн. тонн и северной части Берингова моря - 415 тыс. тонн [1]. В Арктике общий поток грузов, с учетом перевозок в пределах границ СМП (3111 тыс. тонн) и прилегающих регионов (4315 тыс. тонн), составил почти 7,5 млн. тонн [1].

Необходимо подчеркнуть, что транзит по СМП не осуществлял перевозки между иностранными портами. Основные транспортные потоки пролегают между портом Мурманск и портами Юго - Восточной Азии, 14 раз перевозка грузов осуществлялась судами с дедвейтом свыше 20 тыс. тонн, 10 - с дедвейтом более 70 тонн: Мурманск - китайские порты: 492,7 тыс. тонн; Мурманск-порты Южной Кореи: 231 тыс. тонн; Мурманск - Бангкок (Таиланд): 90,3 тыс. тонн.

В 2012 году объем перевозок вырос почти до 4 млн. тонн, в том числе транзитных: с 0,8 до 1,2 млн. тонн, наблюдается тенденция движения-рост. Также в 2012 году был достигнут самый высокий уровень так называемого второго транзита по СМП. В 2013 году было совершено всего 33 рейса (1,160 тыс. тонн), а в 2014 году-24 рейса (240 тыс. тонны). Следует отметить, что они были значительно выше в акватории СМП. Таким образом, 2012 году транспортировано около 4 млн. тонн, в том числе экспорт нефти из Обского залива $-1,5$ млн. тонн, для обеспечения функционирования Норильского промышленного района- около 0,6 млн. тонн, экспорт древесины и шорт-морские перевозки. Например, ледокол «Красин» (Дальневосточное морское пароходство) оказал помощь в восточном секторе СМП 37 судам, которые привезли 125 тыс. тонн грузов, а забрали около 105 тыс. тонн, в том числе мусора, собранного в ходе программы очистки в Арктике.

В 2018 году по Северному морскому пути перевезено 10,691 миллионов тонн грузов. Из них около семи миллионов тонн - с помощью «Атомфлота». К 2020 году планируется достичь рубежа в 40-43 млн. тонн, а к 2024 году необходимо выйти на показатель 80 млн. тонн [2]. Хотя данный показатель является достаточной низким по грузоперевозкам.

Для определения специфики перевозок с использованием маршрутов СМП целесообразно рассмотреть классификацию судов в соответствии с ледовыми классами, регламентируемых Российским морским регистром судоходства (таблица 1).

В соответствии со Стратегией развития Российской Арктики и национальной безопасности до 2020 года одной из важнейших задач является совершенствование транспортной инфраструктуры в районах освоения арктического континентального шельфа с целью диверсификации основных маршрутов поставок российских углеводородов на мировые рынки. Можно отметить, что оборот товаров по северным маршрутам рассматривается как одна из основных характеристик социально-экономического развития Российской Арктики. Факторный анализ грузопотока по СМП показывает, что действие различных сил достаточно противоречивы. Особенно в плане прогнозов как на ближайшую, так и на долгосрочную перспективу. Таким образом, изменение климата, как прогнозируют эксперты, и потепление могут стать причиной «ледокольного свободного судоходства» в Карском море для судов класса Arc7 с ледопроходимостью до 1,5 м. Однако некоторые эксперты прогнозируют понижение температуры в ближайшие 5 лет, что было характерно для конца прошлого века, когда в Карском море помощь ледокола была необходима с декабря по май. Соответственно, в восточном секторе СМП толщина ледового покрова может составлять от 2 до 3 метров, а требования ледового класса к ледоколам могут быть изменены [3].

Арктическое судоходство в последнее время подтверждает, что климатические условия влияют на проход грузовых судов по СМП в различные порты Юго-Восточной Азии на 7-22 дня короче, по сравнению с использованием Суэцкого канала. Данный аспект является важным экономическим достоинством использования данного маршрута. Плату за ледокольные суда вдоль СМП и новый гибкий тариф можно было бы приравнять к оплате проезда по каналу.

В настоящее время можно подтвердить тот факт, что серьезные проблемы формирования эффективной транспортной системы СМП в 90-е годы XX ст. остаются актуальными и в настоящее время. Таким образом требуется серьёзное 
Таблица 1. Ледовые классы судов в России

\begin{tabular}{|c|c|}
\hline Ice1 (ЛУ1) & $\begin{array}{c}\text { Самостоятельное эпизодическое плавание } \\
\text { в мелкобитом разреженном льду } \\
\text { неарктических морей и в сплошном льду в } \\
\text { канале за ледоколом при толщине льда до } \\
0,4 \mathrm{M} \text {. }\end{array}$ \\
\hline Ice2 (ЛУ2) & $\begin{array}{c}\text { Самостоятельное плавание в мелкобитом } \\
\text { разреженном льду неарктических морей и } \\
\text { в сплошном льду за ледоколом при } \\
\text { толщине льда до } 0,55 \mathrm{M} .\end{array}$ \\
\hline Ice3 (ЛУЗ) & $\begin{array}{c}\text { Самостоятельное плавание в мелкобитом } \\
\text { разреженном льду неарктических морей и } \\
\text { в сплошном льду за ледоколом при } \\
\text { толщине льда до } 0,7 \text { м. }\end{array}$ \\
\hline Arc4 (ЛУ4) & $\begin{array}{l}\text { Самостоятельное плавание в разрежённых } \\
\text { однолетних арктических льдах при их } \\
\text { толщине до } 0,6 \text { м в зимнее-весеннюю } \\
\text { навигацию и до } 0,8 \text { м в летнее-осеннюю. }\end{array}$ \\
\hline Arc5 (ЛУ5) & $\begin{array}{l}\text { Самостоятельное плавание в разрежённых } \\
\text { однолетних арктических льдах при их } \\
\text { толщине до } 0,8 \text { м в зимнее-весеннюю } \\
\text { навигацию и до } 1,0 \text { м в летнее-осеннюю. }\end{array}$ \\
\hline Arc6 (ЛУ6) & $\begin{array}{l}\text { Самостоятельное плавание в разрежённых } \\
\text { однолетних арктических льдах при их } \\
\text { толщине до 1,1 м в зимнее-весеннюю } \\
\text { навигацию и до } 1,3 \text { м в летнее-осеннюю. }\end{array}$ \\
\hline Arc7 (ЛУ7) & $\begin{array}{c}\text { Самостолтельное птавание } \\
\text { в спточенных однолетних арктических } \\
\text { льдах при их толщине до } 1,4 \text { м в зимнее- } \\
\text { весеннюю навигацию и до } 1,7 \text { м в летнее- } \\
\text { осеннюю при эпизодическом преодолении } \\
\text { тедяньх перемычек набегами. } \\
\end{array}$ \\
\hline Arc8 (ЛУ8) & $\begin{array}{l}\text { Самостоятельное плавание в спточённых } \\
\text { однолетних и двухлетних арктических } \\
\text { льдах при их талщине до } 2,1 \text { м в эимнее- } \\
\text { весеннюю навигацию и до } 3,1 \text { м в летнее- } \\
\text { осеннюю. Преодоление ледовых } \\
\text { перемычек работой набегами. }\end{array}$ \\
\hline Arc9 (ЛУ9) & $\begin{array}{l}\text { Самостоятельное плавание в спточённых } \\
\text { многолетних арктических льдах толщиной } \\
\text { до } 3,5 \text { м в зимне-весеннюю навигацию и } \\
\text { до } 4,0 \text { м в летнее-осеннюю. }\end{array}$ \\
\hline
\end{tabular}

повышение объемов перевозок и вливаний инвестиций как частного сектора, так и средств государственного бюджета заинтересованных сторон для становления СМП как международной транспортной магистрали. Российская Федерация в настоящее время производит около $12 \%$ мировой нефти и $18 \%$ газа. При этом в ближайшее время добыча нефти в России начнет снижаться, даже с учетом вступления в активную фазу освоения арктических месторождений Ненецкого автономного округа и Печорского моря. Доля России на мировом рынке СПГ сегодня составляет менее $5 \%$, однако в соответствии с целевыми проектами в ближайшие 20 лет до- стигнет $12 \%$ от общего объема рынка. Если по итогам 2016 года доля нашей страны в мировой добыче газа составила $16,2 \%$, то в мировой торговле СПГ - всего 4,5\% [4].

Существует и более привлекательный с точки зрения роста и состояния отношений с Азиатско-Тихоокеанским рынком, а также даже с точки зрения потепления вариант, который означает, что восточный сектор СМП будет доступен для судоходства без ледоколов в течение 5-6 месяцев. Рынок Азиатско-Тихоокеанского СПГ является малодоступным из-за высоких транспортных расходов и общих экономических рисков доставки из Западной Сибири и Баренцева 
моря (рис.1). Тихоокеанский рынок далеко, а ледокольная поддержка в Арктической транспортной системе необходима практически круглый год.

Североамериканский рынок является наиболее предпочтительным для России, поскольку на европейском рынке мы активно укрепляем «трубную» связь. Однако до 2030 года ограничение будет как минимум “нечувствительным" к экспорту в связи с собственными ресурсами. Кроме того, ближайшим соседом и союзником США является Канада, и у нее есть запасы нефти, которые в три раза превосходят запасы России.

Следующая важная проблема в развитии СМП связана с толщиной льда и шириной канала. Ледоколы типа «Арктика» образуют ледяной канал 33-34 метра, при этом ширина танкера класса «Панамакс» достигает 40 м. (дедвейт до 80 тыс. тонн). Например, суда класса Arc7 могут двигаться без ледокола, т.е. независимо. Количество таких судов постоянно растет и флот пополнился 5 танкерами класса YamalMax (танкеры данного класса соответствуют судам класса Arc7), которые могут самостоятельно перемещаться в лед толщиной 2,1 метра. По прогнозам, к 2020 году численность крупных Arc7 увеличится до 40 судов. Чтобы обеспечить их безопасный проход в Обской губе, планируется создать система управления движением судов [5].

Теоретические и экспериментальные исследования позволили предложить новые инновационные технические средства для прокладки широких каналов (50 м и более) во льду. Такие каналы могли бы использоваться практически всеми крупными судами, в любых условиях, включая сжатие льда. Создание традиционного ледокола шириной 50 м приводит к значительному увеличению сопротивления льда и, следовательно, к увеличению энергопотребления. Поэтому при создании нового ледокола наиболее важной задачей является снижение ледостойкости [6]. Эта задача была выполнена путем создания нового ледокола в виде многослойной конструкции на одной платформе. Предлагаемый ледокол имеет три-четыре корпуса, относительно небольшие, поэтому общая площадь судна значительно увеличена.

Также планируется улучшение судоходства не только по морским путям, но и по прибрежной зоне и основным рекам, что позволит укрепить потенциал развития водного транспорта, торговли и туризма. СМП может стать одним из основных грузовых маршрутов, а сокращение ледового покрова может способствовать развитию нефтегазового шельфа. Однако эксперты предупреждают о новых рисках. Так, под влиянием совокупности факторов, таких как повышение уровня моря, таяние вечной мерзлоты и усиление воздействия волн в результате увеличения площадей, покрытых водой, могут возрасти эрозия береговых линий в Арктике. Все это создает очень опасное воздействие на всю инфраструктуру, особенно на порты [3].

В заключении следует отметить, что обеспечение положительной динамики грузопотоков по северному маршруту и защита националь-

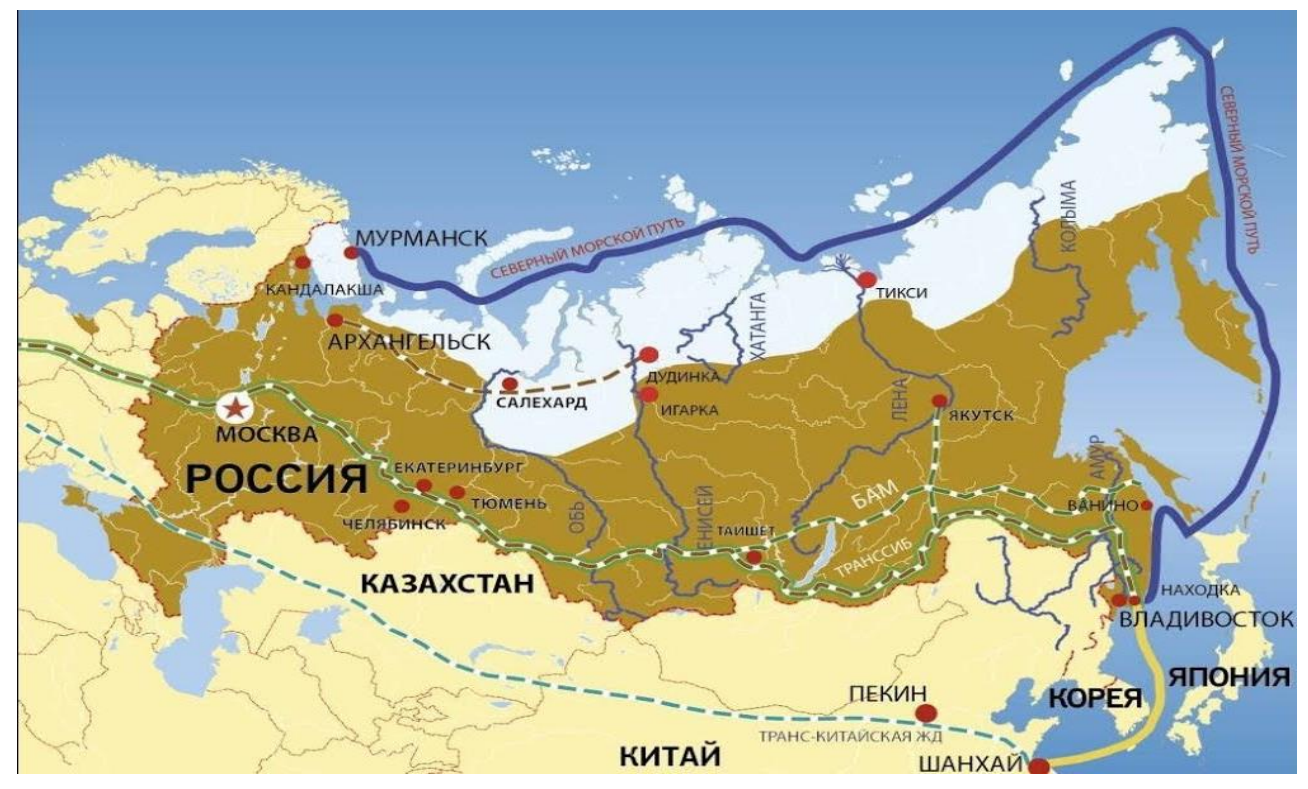

Puc. 1. Маршрут Северного морского пути 
ных интересов в арктических водах должны обеспечиваться комплексом мер, таких как:

- Оценка изменения климата и система карт для различных ледовых условий в Арктике на долгосрочную перспективу.

- Разработка комплексного сценария прогноза движения по Северному морскому пути на период до 2030 года в зависимости от изменения условий на основных мировых энергетических рынках.

- Создание благоприятного режима для международного судоходства, включая использование портовых особых экономических зон; создание морского транзитного коридора «Европа - Азия».

- Совершенствование арктических коммуникаций, особенно в действующих портах (Хатанга, Диксон, Тикси, Певек и др.)

- Создание привлекательных условий для пользователей СМП (тарифное регулирование, страхование, система безопасности и др.).

\section{Библиографический список}

1. Мехайльченко В.В. Северный морской путь - национальная транспортная магистраль России в Арктике. Российский Север: модернизация и развитие. М.: Центре стратегического партнёрства, 2012. С. $350-353$.

2. Покровский А. Северный морской путь станет атомным. URL: https://tsargrad.tv/articles/severnyj-morskojput-stanet-atomnym_174202

3. Коржун В.А. Глобальное потепление - реальность или политизированный миф. М.: ИМЭМО РАН, 2009. C. 191.

4. Евдокимов Г. П., Высоцкая Н.А., Костылев. И.И. Перевозки по Северному морскому пути и развитие арктического флота. IV Всероссийская морская научно-практическая конференция. 2012. МГТУ.

5. Geoinformation system use for transportations planning in water area of Northern Sea Route// IOP Conf. Series: Earth and Environmental Science 194 (2018) 072010 IOP Publishing doi:10.1088/1755-1315/194/7/072010 - C.5

6. Шеппард. Д. Рынок сжиженного газа становится глобальным. Financial Times. 2015. 